\title{
An Evaluation of the Impact of District Assembly Common Fund for the Disable: A Study of the Asuogyaman District
}

\author{
Ewurabena Aniniwa Darkwah $^{1^{*}} \quad$ Dennis Nii Ayeh Mensah ${ }^{2^{*}} \quad$ Evans Opoku Mensah $^{3 *}$ \\ 1. School of Governance and Public Administration, Ghana Institute of Management and Public Administration. \\ P.O Box AH 50, Achimota, Accra Ghana \\ 2. Web Sciences Center, School of Computer Science and Engineering, University of Electronic Science and \\ Technology of China, Chengdu 611731, P.R. China \\ 3. School of Management and Engineering Science, University of Electronic Science and Technology of China, \\ Chengdu 611731, P.R. China
}

This research is self-financed

\section{Abstract}

Society often frowns on things considered to be odd and abomination and have shown this in the treatment of Persons with Disabilities (PWDs). In developing nations such as Ghana it is quite common to find disabled at street corners begging for arms. This study seeks to assess the impact of the District Assembly Common Fund (DCF) on the socio-economic lives of PWDs and recommend ways to improve the policy. Using a double bowelled technique of both qualitative and quantitative methods of studies. 100 PWDs were selected and interviewed whiles 5 employees each of the social welfare and district assembly workers were also interviewed and analysis were done using Statistical Package Service Solution. Results were generated through descriptive and analytical statistics. The findings show that education; employment and income levels were too low among PWDs to impact positively on their socio-economic status hence more needs to be done to aid in their right to socio-economic freedom. Although the mean monthly income of respondents was GHC 145.20, 56.7\% earned between GHC80.00 to GHC120.00, below the national minimum wage whereas at 2014 was GHC184.80.00 per month. Mean monthly income was higher among respondents who had some level of education compared to those who weren't. The mean amount of money received from the fund was GHC 250.00. Although the PWDs stated that the funds were inadequate they iterated that it went a long way to aid in their livelihood. About $75 \%$ indicated that majority of their income was used mostly on food with the rest used for healthcare and other activities. Challenges associated with managing the District Assembly Common Fund ranged from several dimension spanning from the irregular and untimely desperation of funds to the poor administration of the funds. More so, social workers lack proper data and control over the identification of the PWDs in itself. We also found out that some PWDs had no idea of the scheme let alone to partake in it. It is encouraged that future studies should be directed towards a well-structured system for the distribution of items to the PWDs.

Keywords: Poverty, Person with Disabilities, District Assembly Common Fund, Asuogyaman

DOI: $10.7176 / \mathrm{DCS} / 9-1-07$

\section{Introduction}

All over the world every society has a fraction of individuals considered as Disabled. These persons either have loss of sight, hearing, speech, physical, intellect, and emotion, due to their disability they are unable to function and, in most cases, do any economic activity which renders them poor and abandoned. In developing countries however, this situation is far more prevalent with more PWDs left to their faith. Before long some were considered a curse and were either left for death or killed. However, in Ghana the situation is a little bit moderate and with the country being part of the UN several policies and activities that have been put in motion to equipped and empower PWDs. Thus, the need for social grant which brings about these improve access to social amenities, services and benefit which empowers PWDs to be self-sustaining and equipped (Neves et al.,2009). Accordingly, the World Bank Organization describes poverty as "Poverty is hunger, poverty is lack of shelter, and poverty is being sick and not being able to see a doctor. Poverty is not having access to school and not knowing how to read, Poverty is not having a job, is fear for the future, living one day at a time. This definition very much describes the situation of most PWDs in the bid to promote the importance of the need to treat and include the PWDs the United Nation's International Day for PWDs. This facilitated the theme to empower persons with disabilities and ensure inclusiveness and equality this together with several activities brought about the need to cater and properly manage PWDs.

Asuogyaman District was created under local government instrument LI 1431 of 1988 as a result of Ghana Government re-demarcation exercise carried out to decentralize and operationalize program in the country from the defunct Kaoga District, which had Somanya as the capital. According to the District Population census carried out in 2010 the district has about 2.4 percent of the district's total population which has one form of disability or the other. Female population with disability was found to be a little higher $(2.5 \%)$ than their male's counterpart which was (2.3\%). The District Assembly Common Fund is an institution of a pool of resources 
created under Article 252 of the 1992 constitution of Ghana. Its core aim is to efficiently and effectively disburse funds to the individual District Assembly and Metropolitan, Municipal and Districts (MMDs), an allocation of $5 \%$ of the national revenue seated aside to help in the development of the individual communities. The disbursement which is scheduled to be done quarterly in installments has an allocation of $2 \%$ to persons living with disability hence Article 41 of the Disability Act, 2006 (Act 715) provides for the establishment of the National Council on Persons with Disability (NCPD), whose mandate is to propose and evolve policies and strategies to ensure the inclusion of PWDs in national development. Several agencies under the authority of Minister for Employment and Social Welfare in cooperation with several groups such as District Assembly Common Fund (DACF), National Council on Persons with Disability (NCPD) and others seeks to the disbursement and management of funds effectively.

\section{Literature Review}

Persons with Disabilities can be found all over the world. They are largely marginalized and not represented in the socioeconomic, cultural and political sphere of the society (Fitzgerald, 2007). These individuals are considered to be often not employed and have or low educational background (Filmer, 2005) this result in low economic activity and in most cases no activity at all thereby rendering them liabilities (Mitra et al.,). Government of Ghana in an effort to reduce the piety of the PWDs thought it wise to establish a fund, which seeds from the DACF would serve as a bedrock for these individuals and provide for them some tools or equipment for improving their livelihood. It can be noted however, that all over the world social grants are given as a source of empowering tool to help reduce the plight of the vulnerable. In most developing countries, most of these social welfare and grants are done with the aid and support from foreign donors such as the UNAID, DANIDA, JICA, World Vision International, ROTARY and more. However, several challenges obstruct the implementation of these projects which is $100 \%$ donor sponsored and, in some cases, a total halt. These challenges have either been lack of communication or the proper engagement with stakeholders. Moreover, the government of Ghana has its several challenges spading from mismanagement to inadequate funds which serves as blockages for the implementation of these social and empowering programs. The role donors play in this social program most especially in our part of the world cannot be over emphasized. The institutionalization of the 2\% District Assembly Common Fund has gone a long way to help promote and empower the PWDs but according to ((Ghana Statistical Services, 2012; Sackey, 2009) the 2\% didn't have any clear relation between the program and its impact on beneficiaries. Also, availability of data pertaining to the implementation challenges and problems are quite scanty even though according to SEND Ghana report, about 55\% of Metropolitan Municipal Assemblies (MMA) in 50 districts across four administrative regions (Greater Accra, Northern, Upper East and Upper West) in Ghana had implementation challenges (SEND Ghana, 2010). It must be stated however that in 2017 the government restructured the program by providing PWDs with items that will aid in their fight to financial freedom instead of the previous monies handed to them. In Asuogyaman especially and in every other district the social welfare organ is tax with this mandate to manage and provide a detail on the PWDs as well as the items they might need. However, since this is a new initiative these social workers were not well equipped, trained and in some cases, have little or no knowledge on the management and how to deal with PWDs. This necessitated the need to assess the impact this policy change has on PWDs.

\subsection{Impact of Monetary Payment}

Evaluating the impact of the money payment system it was found to be very problematic since it may have different objective and design. Moreover, this form of payment wasn't effective in the objective of the program as it sorts to give socioeconomic relief, it was found to do the opposite as most PWDs tend to spend the money before any commercial(business) financial step is taken. However, in the reduction of child poverty, Barrientos and DeJong (2006) found that cash transfer is an effective means but all this depends on the contribution giving to a person which is not enough (Tabor, 2002). In furtherance cash transfer outcome as identified by (Arnold et al.,2011) as follows:

- Raising living standards of the poor

- Human development or human capital

- Economic development and inclusion growth

- Empowerment and gender equality

- Climate change and national disasters

Facilitating social cohesion and state building

Further studies by Blomquist and Mackintosh (2003) suggests some of the features of a good monetary payment in developing countries are managing program type to need, beneficiary selection, program generosity, promoting gender equality, securing and sustaining political support and building administrative support. Social grants support development such that it enables beneficiaries and family members to have improvement in consumption and welfare (Neves et al., 2009). This can also improve the status of beneficiaries within the 
locality

\subsection{Impact Evaluation of Livelihood Items}

Impact evaluation is an assessment of how the intervention being evaluated affects outcomes and, in this instant, the PWDs. Moreover, several outcomes come into play which brings about intended or unintended circumstances. In this study which focus on the impact of the new policy change has the counterfactual been the before when money was paid to them and the now which comprises PWDs been giving startups or items to help alleviate them from poverty (Baker, 2000.)

\subsection{Socio-economic status of Persons with Disabilities}

In developing countries poverty has a direct link with disability as results of the problems they face due to societal, economic and cultural issues. PWDs are seen to perform poorly in areas that might give them economic freedom. Their participation in education, employment, social life and asset possession don't seem to be encouraging enough to alleviative them from poverty (Fitzgerald, 2007). Relatively, PWDs have higher risks of not being utilized (not resourceful) than nondisabled persons. Within the identified people, there's a major gap between gaining employment among PWDs and non-PWDs. it's been found within the U. S. that 38\% of PWDs got utilized as compared to $78 \%$ of the non-disabled population in 2005 . That very same year reported a $23 \%$ financial condition rate among Americans PWDs at operating age as compared to solely $9 \%$ of the non-disabled cluster (Palmer, 2011). In Zambia, the speed of employment among disabled and non-disabled were $45 \%$ to $56.5 \%$ in 2005 (World Health Organization, 2011). Consistent with McClain-Nhlapo (2007), United Nations agency information estimate that, among 5 world's poorest individuals in society, one could accept some type of incapacity. Moreover, the background paper for the Organization for Economic Co-operation and PWDs Development (OECD) in 2009 shows that in membership countries, employment of PWDs has fallen behind different teams despite measures to integrate them. On the typical, the financial gain of PWDs in OECD countries are twelve-tone system below national averages. The personal income for PWDs in these countries is at $22 \%$ (OECD, 2009). In Australia, it's been reported that 45\% of people living with disabilities live either close to or below the personal income. This rate over double the OECD average rate. It is estimated that countries with high rate of poverty are primarily found hence PWDs in these countries are more vulnerable. Countries in South and East Africa recorded the highest number poverty and disabilities. Most of these poor communities' experience food crises as results of food insecurity in most countries within the region. In geographic area, maternal and child mortality continues to account for deaths in most societies. Access to health, education and different services that may improve people 's welfare is additionally lacking in these countries (Devereux et al., 2005). Filmer (2008) conducted a survey on 14 households from 13 countries in developing countries. The analysis suggests that people with disabilities lack the human capital to earn higher financial gains. This is often attributed to the very fact that they have very little possibility of starting school. Disabilities limit these children from schooling over different factors like space of residency (rural or urban), gender and economic standing. It is essential to notice that, poor individuals have the probability of turning into disabled through lack of access to health services, inadequate nutrition diet and unsafe environment. PWDs additionally face a lot of vulnerabilities due to financial condition such disable individuals are discriminated in several context. This emphasizes the link between disabilities and long run-poverty and creates a link between financial freedoms among PWDs (Babson et al., 2001; Elwan, 1999; Saunders, 2005). It affects the complete wellbeing of such an individual. Moreover, families with PWDs have a high rate of financial burden as compared to families without them with higher rate of $15 \%$ to $44 \%$ respectively. The consumption level of these PWDs families is relatively higher compared with their families without them.

\subsection{Social Protection: Definitions, Concepts and Rationale}

Globally, social protection is increasingly receiving policy attention for its importance in protecting individuals, households and poor communities from risk and shocks like loss of breadwinners and natural disasters. It is adopted as a developmental tool by most countries towards the attainment of the Millennium Development Goals. The massive acceptance of this was in the year 2000 (Chinsinga, 2007). Some literature (Devereux et al., 2005) reveals that, the introduction of social protection builds on the 1980 Safety Agenda Program. It also uses ideas and experiences derived from — sustainable livelihood approach, vulnerability analysis and multidimensional nature of poverty in the 1990s. Social protection has widely been defined by most researchers. Internationally, it has no precise definition. This study, therefore, employs the one used by Sabates - Wheeler and Devereux (2007) and 2006 Conference on Social Protection in Zambia. Their definition of the concept stands to be one of the definitions which focus on a broader perspective beyond economic risk and vulnerability. It is however stated that: Social protection describes all initiatives that transfer income or assets to the poor, protects the vulnerable against livelihood risks and enhances the social status and rights of the marginalized; with the overall objectives of extending the benefits of economic growth and reducing the economic or social vulnerability of poor, 
vulnerable and marginalized people (Sabates - Wheeler \& Devereux, 2007) Social protection has widely been debated by researchers and international agencies to include different type of components. These components are referred differently by different studies but bear the same explanation and concepts. United Nations Children Fund (UNICEF) has developed a social protection strategy framework to be adopted in overcoming exclusion and economic vulnerabilities among poor people. This strategy identifies four key components of social protection including social transfers program to ensure access to services, social support and care services and legislation and policy reforms '(UNICEF, 2008). However, according to the study by Sabates - Wheeler and Devereux (2007), Social protection is categorized into four measures of operation such as provision measures, preventive measures, promotion measures and transformative measures.

\subsection{Social Assistance (Provision measures)}

Provision measures are sometimes referred by some writers as social assistance. For instance, Woolard (2003) showed that, Social Assistance is the benefits that vulnerable groups like PWDs, orphanages, children from poor households and the elderly receive from the government of a country. The Organization for Economic Cooperation and Development (OECD) conducted a study on Social Assistance in its member countries. According to the report of the study, three types of Social Assistance emerged from these countries including general assistance, categorical assistance and tied assistance. The general assistance is a cash transfer benefit that targets poor people below a minimum income level of that country. Categorical assistance on the other hand targets specific group of people. Example is a group that has experienced disaster such as fire outbreak, earthquake and flood. These groups of people may be above the minimum income level. Finally, tied assistance 'involves provision of free goods or services. It can also be at a subsidized price. A typical example is housing project for citizens (Eardley, Bradshaw, Ditch, \& Gough, 1996). The vision of Social Assistance has now changed from food aid approach to cash transfer program with support of donor and multilateral agencies. Funding of this program comes with evidence-based support to implement on pilot base. The leading agencies funding most cash transfer program in Africa include UNICEF, DFID from United Kingdom, GTZ from Germany, SIDA from Sweden, DANIDA from Denmark and the World Bank (United Nations Development Program [UNDP], 2013). In Africa, previous research has shown that cash transfer program usually covers few beneficiaries as compared to the total number of people in that group. Cash transfers targeting children can improve their wellbeing if it is given to the mother. Although fathers are seen as head of families, the mother helps to calm the pressure in the house. It is also important to note that most cash transfer program with complex conditionality is not able to reach vulnerable groups (Villanger, 2008). In view of this, most cash transfer program will be successful if they are unconditional, non-contributing and non-tested. It is, therefore, financed by public funds.

\section{Methodology}

\subsection{Objective of Research}

To ascertain the impact of items distribution to PWDs as compared to the previous method of giving monies. To ascertain the challenges facing the fund disbursement and how it affects the PWDs.

\subsection{Research Design}

The study used various methods and techniques both secondary and primary information that aided in the collecting, analyzing and evaluation of data. It comprised details of the methods including the study design, study area, target population, sampling techniques and sample size, data collection techniques and plan of data analysis that were used for the successful arrival of the objectives. The study survey is in the form of a crosssectional study in which data was collected once across a population through sampling. 100 PWDs were selected using convenience sampling technique, to which questionnaires were administered, 5 staffs of social welfare were interviewed and 5 assembly staff using an open and closed ended questionnaire with the help a guide. In the development of the questionnaires, several literatures were considered.

\subsection{Study population}

The participants in this study were Persons with Disability who have in one way or the other benefited from the $2 \%$ allocation of the PWDs in order to have a comprehensive look into how the fund has improved their livelihood with respect to the previous and the current disbursement. 
Table 1. Population by type of locality, disability type and sex

\begin{tabular}{|l|l|l|l|l|}
\hline Disability Type & Number & Percent & Male & Female \\
\hline Without Disability & 459.4 & 97.6 & 97.7 & 97.5 \\
\hline With Disability & 2,327 & 2.4 & 2.3 & 2.5 \\
\hline Sight & 955 & 41.0 & 41.7 & 40.5 \\
\hline Hearing & 351 & 15.1 & 14.7 & 15.4 \\
\hline Speech & 360 & 15.5 & 17.8 & 13.5 \\
\hline Physical & 784 & 33.7 & 34.4 & 33.1 \\
\hline Intellectual & 292 & 12.5 & 13.8 & 11.5 \\
\hline Emotional & 214 & 9.2 & 9.2 & 9.2 \\
\hline Others & 181 & 7.8 & 7.9 & 7.7 \\
\hline Total & 98,046 & 100.0 & 100.0 & 100.0 \\
\hline
\end{tabular}

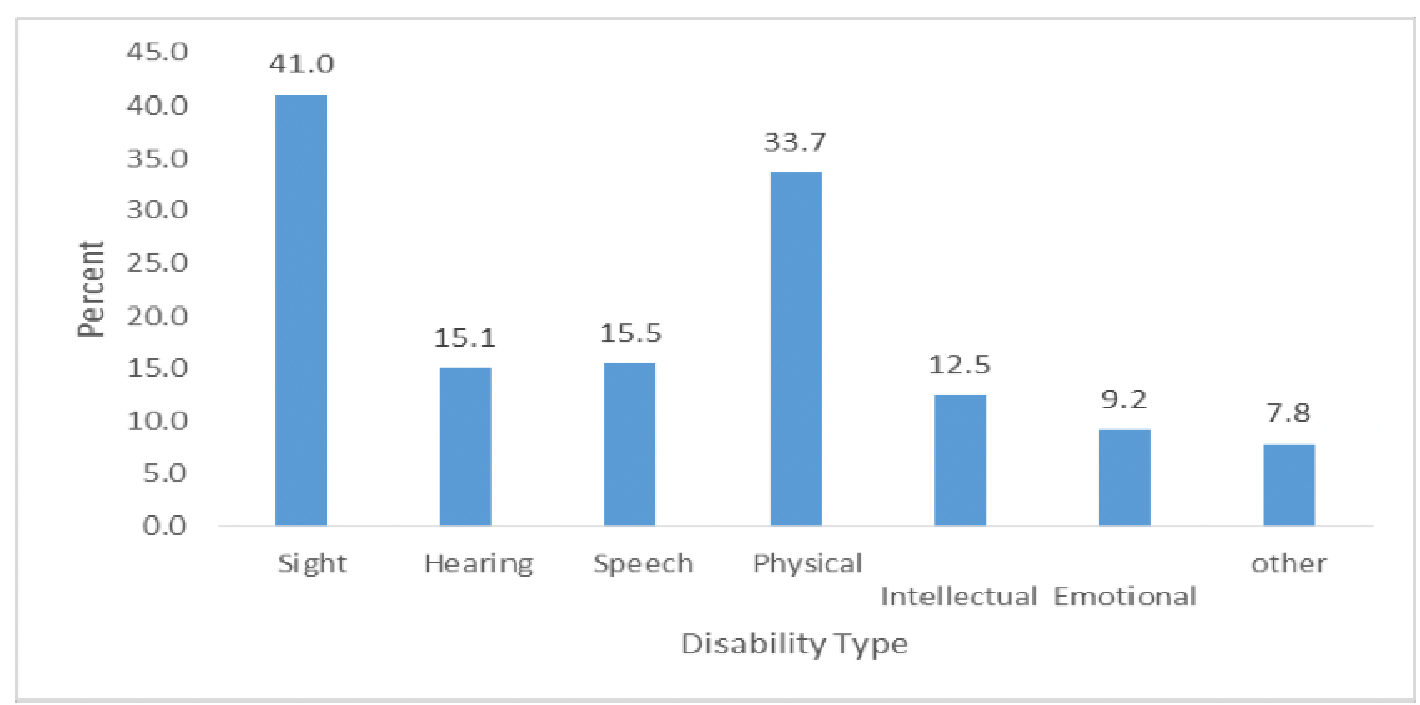

Figure 1. Population by type of disability

Source: Ghana Statistical Service, 2010 Population and housing census

\subsection{Sampling techniques and sample size}

Sampling technique is used to select participants and this is because of the large number used to select participants from a huge population sample. It concerns the selection of a subset of individuals from within a population to estimate characteristics of the whole population (Kumekpor, 2002). Several characteristics were taken into consideration in this selection. This is done to ensure a representation of the entire population. The idea is to help identify a small sample that will represent the entire population (Creswell, 2013). Purposive sampling is used to select sample units within the segment of the population with the most information on the characteristics of interest (Guarte \& Barrios, 2006).

\subsection{Data collection techniques and tools}

The study used different instruments to obtain information from the respondents. Copies of questionnaires were used to obtain data from participants. This study, to a large extent, used primary data and where necessary some secondary data too. The primary data consisted of the responses to the administered questionnaires. The secondary data were records from the Department of Social Welfare about the beneficiaries of the fund in the Asuogyaman District. The interview questionnaires were open and close ended which was structured based on the objectives of the study. The respondents were guided by the researcher and research assistant. They explained clearly the interview questionnaires to the respondents. The Disability Common Fund Management Committee in the Asuogyaman District was included in the study. They answered open ended questions on the management of the fund, challenges they faced in handling the funds and suggestions on how the programs can be improved. Researchers have established the fact that respondents are very unwilling to talk to unknown persons on matters concerning their lives, particularly PWDs. Therefore, PWDs may find it reluctant to reveal information to unknown people due to stigma and discrimination.

\subsection{Pre-testing}

The study methods were pretested to overcome any inconveniences. The pretesting helped the researcher to 
make some adjustment in the data collection tools where it became necessary prior to the implementation of the study. Pretesting consisted of beneficiaries of the DCF fund. The pretesting asked questions on socioeconomic status of beneficiaries and the impact the DCF had on their lives after enrolment in the program.

\subsection{Data analysis procedure}

All Data gathered from respondents were checked by a field supervisor to ensure completeness and consistency. The information was then kept confidential; only the principal investigator and project supervisor had access to the information this was necessary because most PWDs were quite concern about their privacy. In analyzing the data gathered from the open and closed ended questions administered to the officials of the DCF program, a document was printed out and read thoroughly to ensure all questions were accurate, concise and clear. The data was then grouped into categories from themes occurring several times. Contrary to the previous, data collected from the PWDs were analyzed using descriptive statistics. Statistical techniques such as means, standard deviations, regression, and variance were computed where necessary. Also, p-value was used to establish a relationship between the socio-demographic variables and income level of the respondents. Statistical Package software for Social Sciences Software (SPSS) was used in the analysis phase of the study. The final result of the study was presented using graphs and tables where necessary.

\section{Findings}

\subsection{Evaluation Approach}

There several approaches that can be considered when evaluating a project. Formative evaluation is an on-going process that allows for feedback to be implemented during a program cycle (Boulmetis \& Dutwin 2005). It aids in the concentration on examining and changing processes as they occur and provide timely feedback about programs. While summative evaluation is done at the end of project and provides an overall description of how effective and efficient the project has been. Considering these types and taking into consideration the project objective it is imperative to conduct a summative evaluation using an Impact Evaluation method which is broader and assess the overall effect thus the intended and unintended objectives of the project. And to a larger extend how the change of policy from giving monies to PWDs to providing them with the necessary tools help equip and improve their livelihood. Impact Evaluation conducts a compressive and detailed in-depth assessment of the whole program hence a better evaluation method for the study.

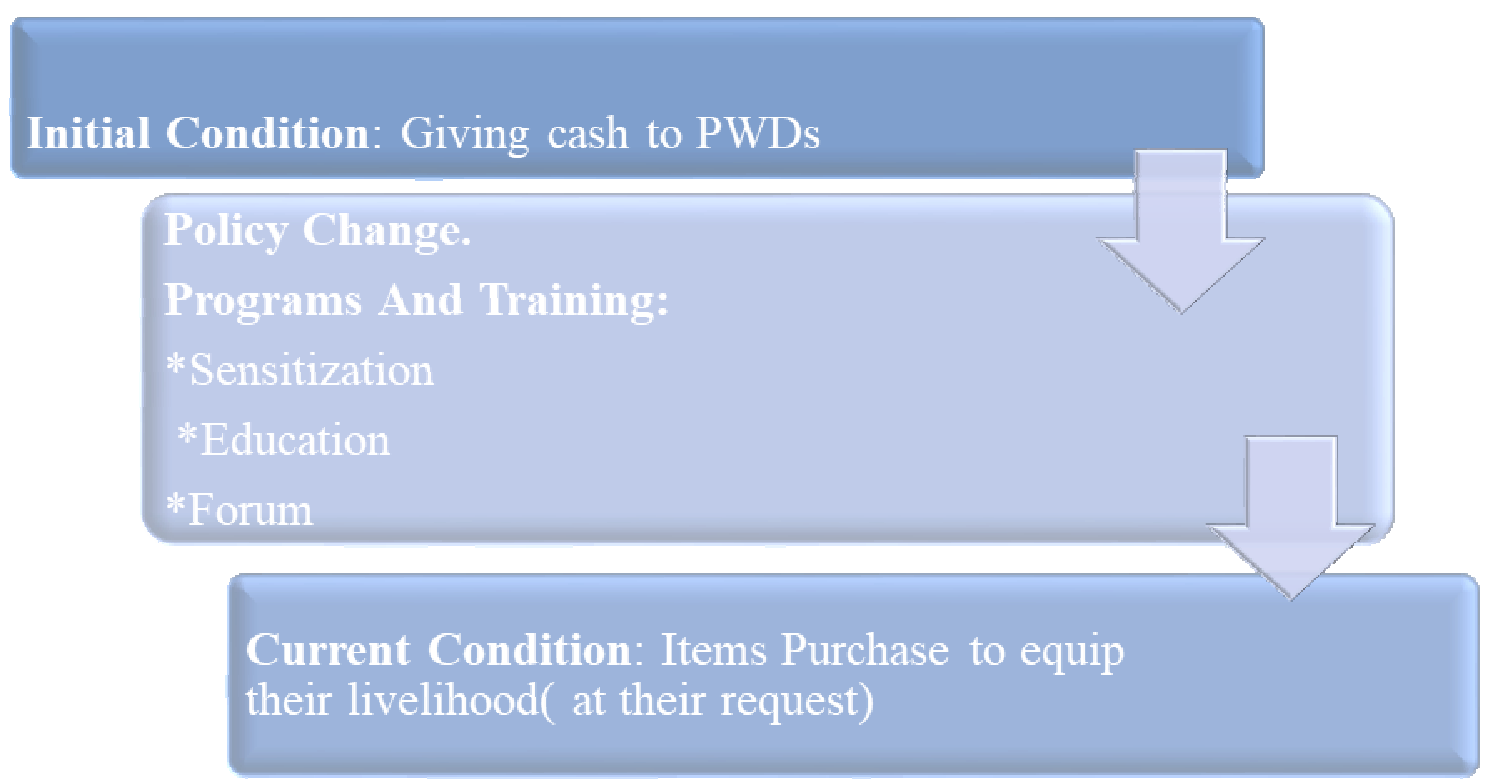

Figure 1. Theory of Change

Change process of the project from 2015-2018

\section{Discussion}

\subsection{Socio-economic and Demographic Characteristics of PWDs in Asuogyaman}

The findings of the study showed that males dominated within the study than females with majority between the ages of 18 to 30 years with mean age of 20 years. $10 \%$ had primary education with $25 \%$ having no formal education. However, $18 \%$ of respondents had tertiary education. The academic qualifications of respondents are comparatively low and concur with the assertion created by Fitzgerald (2007) that, PWDs participation in 
education isn't that encouraging to help in the alleviation of poverty in their community. The findings from the study further advised that Persons with Disabilities who were able to climb the ladder of obtaining a tertiary education were more likely to get jobs at the government or private sectors. This conjointly confirms other studies that stress lower employment among PWDs (McClain-Nhlapo, 2007; Mitra \& Sambamoorthi, 2006; Palmer, 2011). It reinforces the findings from the 2011 World report on disability that, there's lower employment among working age disables than non-disables (WHO,2011). These findings may well be attributed to the low level of education that prevents them from accessing employment as stated by (Lwanga-Ntale, 2003) in Republic of Uganda and World Report on disabilities (WHO, 2011) a 1995 report by United Nations. According to Lwanga-Ntale (2003), it's usually perceived in Republic of Uganda that disable women are unable to perform ménage chores, farm and look after themselves, thus preventing them from getting married. According to the Global Health Organization (2014), there's a restricted access to assistive devices among people that need them. This can be attributed to the high value of devices, limited production including scarce trained personnel to manage such devices. (53.9\%) of the respondent required the use of assistive devices such that $15 \%$ and $0.5 \%$ uses clutches and white canes respectively. The findings once more showed that $55.9 \%$ majority had supportive devices which weren't provided and maintained by the DCF but concluded that more needed to be done as less people were listed on the DCF program and funds were not readily available. However, efforts must be made to extend the speed of access to all PWDs in Asuogyaman.

\subsection{Monetary Obligations of Dependents}

The presence of dependents on PWD can additional worsens the monetary burden on the person which can adversely have an effect on the standard of living an effect on the disabled person. Research on the socioeconomic lifetime of PWDs has not been given a lot of attention in Africa particularly within the SubSaharan region. However, the analysis conducted on inclusion of PWDs in actions to scale back financial constraints and hunger emphasizes the very fact that families that are being headed by a disabled person are possible to be poorer by $15 \%$ to $44 \%$ than the one headed by non-disabled (McClain-Nhlapo, 2007). Results from this study indicated that the mean monthly financial gain among respondents was GHC 145.20. With this financial gain, it falls below the national monthly minimum wage of GHC 184.80. This confirms the findings from OECD countries that have established that PWDs earl below national averages (OECD,2009). It concurs with another study that established the fact that supply of disabilities predicts low financial level (Filmer, 2008). Despite the findings there is no significant relationship ( $p>0.05)$ between gender and monthly financial gain. However, the study showed that females earned less financially than males (GHC 120.45 versus 135.24). This therefore, confirms the 2011 World report on PWDs that disable girls commonly earn less than men with disabilities (WHO, 2011). Mean monthly financial gain was higher among respondents with tertiary qualification than those with no formal education GHC 600.00 verse GHC 300 respectively.

\subsection{Impact of Common Fund on the socioeconomic lifetime of PWDs within the Asuogyaman District}

The direct impact of social grants to vulnerable population isn't restricted to their direct pocket expenditure on food and shelter but extends to different areas of their lives. It can extend to primary targets such as immediate family and community members (Barrientos \& DeJong, 2006). DCF and other money benefits given to the PWDs are not enough to relief them of their financial burdens(Villanger, 2008). Investigating the importance of the impact of the DCF is key to it sustainability. Results from the study showed the extent to which DCF affects the socioeconomic lifetime of PWDs within the Asuogyaman District and how the new process of purchasing items compared to the previous monetary payment impacts their livelihood. Findings indicated that majority (75\%) of respondents had received the DCF but $12 \%$ indicated that they had no knowledge about the distribution. it was found that 750 million to 1 billion of vulnerable population in developing countries benefited from money transfers (Arnold et al., 2011). About $80 \%$ of this study respondent received the fund once a year. This shows the level of frequency of the fund to impact on the socio-economic lifetime of PWDs and more importantly how this new structure would go along to improve they livelihood and finances.

In furtherance money transfer programs in Africa usually helped a few beneficiaries during a cluster (Villanger,2008). Receiving the DCF once a year from a fund that is expected to be quarterly had the implications that there were restricted funds to help several beneficiaries. Again, impact of the money transfer on the socio-economic lifetime of beneficiaries relied on the size of the funds received and also the contribution to family financial gain (Tabor, 2002) hence the importance of the new structure. Findings indicate that majority $(60.2 \%)$ of PWDs within the Asuogyaman District received GHC 250.00 to 500.00 among the amount they were entitled and $21 \%$ received GHC 150 to 300.00 . Respondents within the study confirmed that the fund was not adequate for them and their families. This confirms what researchers have established regarding the restricted nature of disability grants particularly in developing countries (Gooding \& Marriot, 2009). In Asia for instance, disability grants have been argued to be inadequate to help beneficiaries and family expenditure (Erb \& HarrissWhite, 2002). Congruent with different money transfer programs like Zambia Social Cash Transfer, and 
Mozambique GAPVU (Gabinete Diamond State Apoio à PopulaçãoVulneráve), respondents from this study opined that the DCF has improved their business and farming activities as (Datt et al.,1997; Devereux, 2002; Künnemann \& Leonhard, 2008). Also, the fund helped PWDs within the Asuogyaman District to pay their children fees, aided them to buy assistive devices and also enabled them access health services. This can be consistent with the study by Republic of Kenya CT-OVC analysis Team (2012) that evaluated the money Transfer for Orphans and Vulnerable kids in Republic of Kenya. Despite the quality of the fund, respondents disagreed that the fund supported them in their education and rights but did not give them the needed financial freedom and environment to aid in the participation of national development. Also ensuring that women with disabilities enjoyed the same rights and privileges as their male counterparts and are given the needed support. This is contrary to different studies on money transfer and grants to vulnerable population (Arnold et al., 2011; Blomquist \& Mackintosh, 2003; Künnemann \& Leonhard, 2008). More than 45\% believe that the new DCF system supported them in areas like structural development, engaging in economically viable trade and helping them to educate and support their families (NCPD, 2010). Not all areas in PWDs lives is supported entirely by the fund but it goes a long way to help. The findings additionally indicated that most of the respondents expressed their pleasure with the new structure.

\subsection{Challenges affecting the disbursement of PWDs Common Fund within the Asuogyaman District}

The Disability Common Fund is a vital intervention among social protection policies to alter PWDs inclusion and participation within the national development and conjointly help them to do better economically (NCPD, 2010). However, the quality of the program action and its impact on PWDs lives is dependent on the method of disbursement and management to its usage by beneficiaries. Consistent with a 2010 report by SEND Ghana on the District Assembly Common Fund (DACF), it was found that there was non-adherence to the rules DCF (SEND Ghana, 2010). This study examines the challenges inherent within the disbursement of the disability fund. A Fund Management Committee had been put in place with laid down guidelines for managing the DCF (NCPD, 2010). The DCF committee consisted of the 5 members made up of District Director of financial aid (Chairperson), Special Educator from Ghana Education Services (Secretary), Government appointee from Social Welfare Director one disabled person as a representative from Federation of PWDs and the District Coordinating Director. This 5 made a solid team that guaranteed and seek proper disbursement of the fund particularly with the involvement of a disabled person on the committee to come up with true and honest eligibility criteria and reduce the tendency for corruption as confirmed by Gooding and Marriot (2009). The study additionally indicated that the fund was principally managed and distributed by the financial aid department (Sackey (2009)). According to a SEND Ghana report, regarding 55 of Metropolitan Municipal Assemblies (MMA) in 50 districts across four body regions (Greater Accra, Northern, East and West Region) in Ghana had no Disable Fund Management Committee (SEND Ghana, 2010). The study additional confirmed that the DCF within the Asuogyaman District had a separate bank account where the fund was deposited directly. This once more contradicts with findings by SEND Ghana as nearly common fraction of the districts in their report had no separate bank accounts for managing the DCF (SEND Ghana, 2010). This has the implication that the FMC within the Asuogyaman District works to satisfy the necessity of the fund regulation than different districts within the country as asserted by SEND Ghana. Also, the findings indicate that the particular mandate of watching the employment of the fund is completed by the Fund Management Committee (FMC) that embarks on unannounced rounds to the individual beneficiaries. The team from the national level, like the administrators of the Common Fund conjointly visits the FMC and verifies books and checks issued out. One major challenge that confronted the management of the fund was the late arrival of the funds from the Administrator of the Common Fund such PWDs. Officers continuously visited the FMC protesting regarding this issue. This make PWDs have some mistrust regarding info from the FMC. Despite this, the blame shouldn't be shifted to the administrator since they didn't advisedly delay the fund as if it was in their coffers. The delay however was from the Finance Ministry and government. This may be attributed to restricted funds to be disbursed by the Ministry of Finance (MoFEP). It confirms what researchers have found in developing countries that fund for disabled persons face budget constraints that affects the growth of the programs (Erb \& Harriss-White, 2002; Gooding \& Marriot, 2009; Neves et al, 2009). The FMC, however, expressed worry and cited example from 2013 that, they solely received 2 tranches for the whole year out of the four. There have been continuously excess applications from PWDs within the Asuogyaman District. With restricted funds and excess application, the FMC indicated that they worked on initial come-first serve basis that has the implication that majority of the applications they received wouldn't be attended to. This confirms what majority of PWDs during this study disclosed that, they received the fund once a year. The study additionally found that a few beneficiaries didn't use the fund for the intended functions which can be attributed to the very fact that the fund was deficient to perform such functions. This makes the FMC to line priority and solely more established urgent desires once it arose 


\section{Conclusion}

A study that deals with Persons with Disabilities is prone to a lot of limitations due to the stigma, misconception that society attaches to having disability. PWDs were reluctant in the participation of the study. Whiles participant PWDs who agreed to participate and aid in the research thought of it as a waste of time and a bother. We adopted purposive sampling methods which is quite bias and prone to researcher discretion as participant were chosen based on their characteristics. These limitations were consistent with similar studies. This notwithstanding, measures such as pretesting and training of research assistants helped to minimize the effects these limitations could have had on the conclusions. In sum, males dominated within the study than females. The mean age was 20years with majority between 18 to 30 years. The educational (tertiary) level of PWDs in Asuogyaman was found to be low with majority having some form of basic education. Also, unemployment among PWDs was high since majority had no formal employment and a few engaged in backyard farming. It must be stated emphatically that the new structure is much more appreciated and would go a long way to achieve the much indeed socio-economic and financial freedom of PWDs.

\section{References}

African Union. (2006). The Livingstone call for action (intergovernmental regional conference - Social protection-A transformative agendall). Livingstone, Zambia. Puede consultarse en http://www. helpage. Org/News/Latestnews/VIaB (visitado el 16 de enero de 2007).

Arnold, C., Conway, T., \& Greenslade, M. (2011). Cash transfer literature review. Policy Division, Department for International Development, (DFID) UK.

Babson, O., Rosenblum, D., \& Stevens, A. (2001). Disability, Poverty and Social Security. Economic Policy Research Institute (EPRI), Cape Town.

Barrientos, A., \& DeJong, J. (2006). Reducing child poverty with cash transfers: A sure thing? Development Policy Review, 24(5): 537-552.

Barrientos, A., \& Hulme, D. (2008). Social protection for the poor and poorest in developing countries: Reflections on a quiet revolution. Brooks World Poverty Institute Working Paper, University of Manchester, UK.

Barrientos, A., \& Santibáñez, C. (2009). New forms of social assistance and the evolution of social protection in Latin America. Journal of Latin American Studies, 41(1): 1-26.

Boulmetis, J. \& Dutwin, P. (2005), The ABC's of evaluation: 2nd edition, Jossey Bass.

Creswell, J. W. (2013). Research design: Qualitative, quantitative, and mixed methods approach: Sage Publications Inc, University of Nebraska, Lincoln, US.

Datt, G., Payongayong, E., Garrett, J. L., \& Ruel, M. T. (1997). The GAPVU cash transfer program in Mozambique: International Food Policy Research Institute (IFPRI).

Department of Social Welfare. (2013). Persons with Disabilities registered for Disability Common Fund. Social Welfare. Ministry of Gender, Children and Social Protection. Kumasi, Ghana.

Devereux, S. (2002). Can social safety nets reduce chronic poverty? Development Policy Review, 20(5): 657-675.

Devereux, S., \& Getu, M. (2013). Informal and Formal Social Protection Systems in Sub-Saharan Africa: African Books Collective, Fountains Publishers, Kampala, Uganda. 10(7): 57-75

Devereux, S., Marshall, J., MacAskill, J., \& Pelham, L. (2005). Making Cash Count: Lessons from cash transfer schemes in east and southern Africa for supporting the most vulnerable children and households. Save the Children, HelpAge International, Institute of Development Studies, University of Sussex, London.

Devereux, S., \& White, P. (2010). Social protection in Africa: Evidence, politics and rights. Poverty Elwan, A. (1999).

Poverty and disability: A survey of the literature: Social Protection Advisory Service, World Bank.

Erb, S., \& Harriss-White, B. (2002). Outcast from Social Welfare: Adult Disability, Incapacity and Development in Rural South India. Bangalore, India: Books for Change:. 11(3): 6-5 \& Public Policy, 2(3): 53-77.

Filmer, D. (2005). Disability, poverty and schooling in developing countries: Results from household surveys.

Kumekpor, T. K. (2002). Research Methods \& Techniques of Social Research, Section 1: Sonlife Printing Press and Services, Adenta, Ghana.

Künnemann, R., \& Leonhard, R. (2008). A human rights view of social cash transfers for achieving the millennium development goals. FIAN International, medico international, Bonn/Stuttgart, Germany.

Mitra, S., Pošarac, A., \& Vick, B. (2011). Disability and poverty in developing countries: a snapshot from the world health survey: World Bank.

Sackey, E. (2009). Strengthening the Disability movement in Ghana project, Pilot survey report; Birim, Ho, Manya: Ghana Federation of the Disabled, Accra, Ghana.

SEND Ghana. (2010). Making Decentralization Work for the Poor. Accra, Ghana: SEND Ghana. snapshot from the world health survey: World Bank.

Sultan, S. M., \& Schrofer, T. T. (2008). Building Support to have Targeted Social Protection Interventions for 
the Poorest-The Case of Ghana. Paper presented at the Social Protection For The Poorest In Africa, Kampala, Uganda.

Ghana Statistical Service. (2012). Population \& housing census: Summary report of final results Accra, Ghana: Ghana Statistical Service

Ghana Statistical Service. (2010). 2010 Population \& housing census: District Analytical Report, Asuogyaman District

Guarte, J. M., \& Barrios, E. B. (2006). Estimation under purposive sampling. Communications in StatisticsSimulation and Computation ${ }^{\circledR}, 35(2)$ : 277- 284.

Gooding, K., \& Marriot, A. (2009). Including persons with disabilities in social cash transfer programs in developing countries. Journal of International Development, 21(5): 685-698.

Baker, J. (2000) Evaluating the Impact of Development Projects on Poverty, World Bank.

Kenya CT-OVC Evaluation Team. (2012). The Impact of Kenya's Cash Transfer for Orphans and Vulnerable Children on Human Capital. Journal of Development Effectiveness,4(1):38- 49. Lwanga-Ntale, C. (2003). Chronic poverty and disability in Uganda.

McClain-Nhlapo, C. (2007). Including people with disabilities in actions to reduce poverty and hunger: International Food Policy Research Institute, Washington, US.

Mitra, S., Pošarac, A., \& Vick, B. (2011). Disability and poverty in developing countries: a snapshot from the world health survey: World Bank.

Mitra, S., \& Sambamoorthi, U. (2006). Employment of persons with disabilities: evidence from the National Sample Survey. Economic and Political Weekly, 199-203.

National Council for Persons with Disabilities. (2010). Guidelines for the Disbursement and Management of the District Assembly Common Fund Allocation to Persons with Disabilities: National Council On Persons With Disability, Accra, Ghana.

Neves, D., Samson, M., van Niekerk, I., Hlatshwayo, S., \& du Toit, A. (2009). The use and effectiveness of social grants in South Africa. Institute for Poverty, Land and Agrarian Studies (PLAAS), University of the Western Cape, Cape Town.

Organisation for Economic Co-operation and Development (OECD). (2009). Sickness, disability and work: Keeping on track in the economic downturn - Background paper: OECD.

Palmer, M. (2011). Disability and poverty: A conceptual review. Journal of Disability Policy Studies, 21(4), 210-218.

Sabates - Wheeler, R., \& Devereux, S. (2007). Social protection for transformation. IDS bulletin, 38(3): 23-28.

Sackey, E. (2009). Strengthening the Disability movement in Ghana project, Pilot survey report; Birim, Ho, Manya: Ghana Federation of the Disabled, Accra, Ghana.

Saunders, P. (2005). Disability, Poverty and Living standards: Reviewing Australian evidence and policies. The Social Policy Research Centre, University of New South Wales, Sydney, Australia.

Schubert, B., \& Beales, S. (2006). Social cash transfers for Africa: A transformative agenda for the 21st century: HelpAge International, London.

SEND Ghana. (2010). Making Decentralisation Work for the Poor. Accra, Ghana: SEND Ghana.

Sultan, S. M., \& Schrofer, T. T. (2008). Building Support to have Targeted Social Protection Interventions for the Poorest-The Case of Ghana. Paper presented at the Social Protection for the Poorest in Africa, Kampala, Uganda.

Tabor, S. R. (2002). Assisting the poor with cash: Design and implementation of social transfer programs. World Bank Social Protection Discussion Paper Series, Washington DC, USA.

The Transfer Project. (2013). Countries Retrieved, December 12, 2013. http://www.cpc.unc.edu/projects/transfer/countries

UNESCO. (1995). Overcoming obstacles to the integration of disable people. In R. Hurst (Ed.). Copenhagen, Denmark: UNESCO.

UNICEF. (2008). Social protection in Eastern and Southern Africa: A framework and strategy for UNICEF. UNICEF ESARO, Nairobi.

United Nations Development Programmes UNDP. (2013). Cash Transfer Programmes in Africa. Retrieved November 12, 2013, from http://www.ipcundp.org/PageNewSiteb.do? id=120\&active =3

Villanger, E. (2008). Cash Transfers Contributing to Social Protection: A Synthesis of Evaluation Findings (E. Department, Trans.): Norwegian Agency for Development Cooperation, Oslo, Norway.

World Bank. (2012). Data Countries and Economies: Ghana. Retrieved October 9, 2013, from http://data.worldbank.org/country/ghana

World Health Organization. (2011). World Report on Disability: World Health Organization and World Bank, Geneva, Switzerland

World Health Organization. (2014). Assistive devices/technologies: what WHO is doing. Retrieved May 18, 2014, from http://www.who.int/disabilities/technology/activities/en/ 